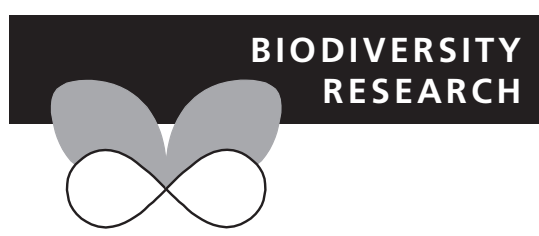

\title{
The importance of correcting for sampling bias in MaxEnt species distribution models
}

\author{
Stephanie Kramer-Schadt ${ }^{1 \star}$, Jürgen Niedballa ${ }^{1}$, John D. Pilgrim ${ }^{2}$, \\ Boris Schröder ${ }^{3,4}$, Jana Lindenborn ${ }^{1}$, Vanessa Reinfelder ${ }^{1}$, Milena Stillfried ${ }^{1}$, \\ Ilja Heckmann ${ }^{1}$, Anne K. Scharf ${ }^{1}$, Dave M. Augeri ${ }^{5,6}$, Susan M. Cheyne ${ }^{7,8}$, \\ Andrew J. Hearn ${ }^{7}$, Joanna Ross ${ }^{7}$, David W. Macdonald ${ }^{7}$, John Mathai ${ }^{9 \dagger}$, \\ James Eaton $^{10}$, Andrew J. Marshall ${ }^{11}$, Gono Semiadi ${ }^{12}$, Rustam Rustam ${ }^{13}$, \\ Henry Bernard ${ }^{14}$, Raymond Alfred ${ }^{15}$, Hiromitsu Samejima ${ }^{16}$, \\ J. W. Duckworth ${ }^{17}$, Christine Breitenmoser-Wuersten ${ }^{18}$, \\ Jerrold L. Belant ${ }^{19}$, Heribert Hofer $^{1}$ and Andreas Wilting ${ }^{1 \star}$
}

${ }^{1}$ Leibniz Institute for Zoo and Wildlife Research, Alfred-Kowalke-Straße 17, 10315, Berlin, Germany, ${ }^{2}$ The Biodiversity Consultancy, 3E King's Parade, Cambridge, CB2 1SJ, UK, ${ }^{3}$ Environmental Modelling Group, Institute of Earth and Environmental Science, University of Potsdam, KarlLiebknecht-Str. 24-25, 14476, Potsdam, Germany, ${ }^{4}$ Landscape Ecology, Department of Ecology and Ecosystem Management, Technische Universität München, EmilRamann-Str. 6, 85354, FreisingWeihenstephan, Germany, ${ }^{5}$ College of Natural Resources, Colorado State University, Fort Collins, CO, USA, ${ }^{6}$ Craighead Institute, Bozeman, MT, USA, ${ }^{7}$ Wildlife Conservation Research Unit, Department of Zoology, Oxford University, The Recanati-Kaplan Centre, Tubney House, Abingdon Road, Tubney, Abingdon, Oxfordshire OX13 5QB, UK, ${ }^{8}$ Orangutan Tropical Peatland Project, Jalan Semeru No. 91, Bukit Hindu, Palangka Raya, Indonesia, ${ }^{9}$ Wildlife Conservation Society Malaysia Program, 7 Jalan Ridgeway, 93200 Kuching, Malaysia, ${ }^{10} A-3 A-5$, Casa Indah I, Persiaran Surian, Petaling Jaya 47410, Malaysia, ${ }^{11}$ Department of Anthropology, University of California, One Shields Avenue, Davis, CA 95616-8522, USA, ${ }^{12}$ Puslit Biologi LIPI, Jl. Raya Jakarta-Bogor Km. 46, Cibinong, 16911, Indonesia, ${ }^{13}$ Faculty of Forestry, Mulawarman University, Samarinda, 75123 East Kalimantan, Indonesia, ${ }^{14}$ Institute for Tropical Biology \& Conservation, Universiti Malaysia Sabah, Jalan UMS, 88400 Kota Kinabalu, Sabah, Malaysia, ${ }^{15}$ Borneo

\section{ABSTRACT}

Aim Advancement in ecological methods predicting species distributions is a crucial precondition for deriving sound management actions. Maximum entropy (MaxEnt) models are a popular tool to predict species distributions, as they are considered able to cope well with sparse, irregularly sampled data and minor location errors. Although a fundamental assumption of MaxEnt is that the entire area of interest has been systematically sampled, in practice, MaxEnt models are usually built from occurrence records that are spatially biased towards better-surveyed areas. Two common, yet not compared, strategies to cope with uneven sampling effort are spatial filtering of occurrence data and background manipulation using environmental data with the same spatial bias as occurrence data. We tested these strategies using simulated data and a recently collated dataset on Malay civet Viverra tangalunga in Borneo.

Location Borneo, Southeast Asia.

Methods We collated 504 occurrence records of Malay civets from Borneo of which 291 records were from 2001 to 2011 and used them in the MaxEnt analysis (baseline scenario) together with 25 environmental input variables. We simulated datasets for two virtual species (similar to a range-restricted highland and a lowland species) using the same number of records for model building. As occurrence records were biased towards north-eastern Borneo, we investigated the efficacy of spatial filtering versus background manipulation to reduce overprediction or underprediction in specific areas.

Results Spatial filtering minimized omission errors (false negatives) and commission errors (false positives). We recommend that when sample size is insufficient to allow spatial filtering, manipulation of the background dataset is preferable to not correcting for sampling bias, although predictions were comparatively weak and commission errors increased.

Main Conclusions We conclude that a substantial improvement in the quality of model predictions can be achieved if uneven sampling effort is taken into account, thereby improving the efficacy of species conservation planning. 
Conservation Trust, 5th Floor, Block B, Wisma MUIS, 88100, Kota Kinabalu, Sabah, Malaysia, ${ }^{16}$ Center for Southeast Asian Studies, Kyoto University, Kyoto, Japan, ${ }^{17} 6$ Stratton Road, Saltford, Bristol BS31 3BS, UK, ${ }^{18}$ IUCN/SSC Cat Specialist Group c/o KORA, Muri b. Bern, Switzerland, ${ }^{19}$ Carnivore Ecology Laboratory, Forest and Wildlife Research Center, Mississippi State University, Box 9690, MS, Mississippi 39762, USA

${ }^{*}$ Correspondence: Stephanie Kramer-Schadt and Andreas Wilting, Leibniz Institute for Zoo and Wildlife Research, Alfred-KowalkeStraße 17, 10315 Berlin, Germany.

E-mails: kramer@izw-berlin.de and wilting@izw-berlin.de

†Present address: Institute of Biodiversity and Environmental Conservation, Universiti Malaysia Sarawak, 94300, Kota Samarahan, Sarawak, Malaysia

\section{Keywords}

Borneo, carnivora, conservation planning, ecological niche modelling, maximum entropy (MaxEnt), sampling bias, Southeast Asia, species distribution modelling, viverridae.

\section{INTRODUCTION}

Species distribution models (SDMs) relate environmental variables to species occurrence records to gain insight into ecological or evolutionary drivers or to help predict habitat suitability across large scales (Elith \& Leathwick, 2009). A diversity of modelling methods have been developed, ranging from rule-based descriptions to complex statistical or machine learning models (Franklin, 2009). Their accuracy depends on the quality and quantity of the input data, from incidental sampling of occurrence records to more accurate presence-absence data (e.g. Baasch et al., 2010; Bateman et al., 2011; Güthlin et al., 2011).

In this context, maximum entropy (MaxEnt) models (Phillips et al., 2006) have become an extremely popular tool to model the potential distribution of rare or threatened species of conservation concern (Wilting et al., 2010a; Clements et al., 2012), to separate ecological niches (Kalkvik et al., 2011) and to forecast future distributions under climate change (e.g. Hu \& Jiang, 2011). MaxEnt uses the principle of maximum entropy to relate presence-only data to environmental variables to estimate a species' niche and potential geographical distribution (Phillips et al., 2006). MaxEnt is popular because it is easy to use and considered to produce robust results with sparse, irregularly sampled data and minor location errors (Elith et al., 2006). Such constraints are common in location data for rare, elusive or threatened species, in data from poorly accessible areas and in museum data (e.g. Graham et al., 2008; Wisz et al., 2008). MaxEnt has the advantage that it uses presence-only data, thus not relying on or requiring data of confirmed absences from specific areas (Li \& Guo, 2011). Overall, these features have led MaxEnt to be considered as one of the best species distribution models in terms of its predictive performance (Elith et al., 2006), especially for species that are rare or have a restricted range (Hernandez et al., 2006; Pearson et al., 2007).

One fundamental assumption of SDMs in general and hence also MaxEnt models is that the entire area of interest has been systematically or randomly sampled (Phillips et al., 2009; Royle et al., 2012). In practice, MaxEnt models are almost invariably built on occurrence records that are spatially biased towards more easily accessed or better-surveyed areas (Phillips et al., 2009; Ruiz-Gutierrez \& Zipkin, 2011). Furthermore, the increased use of telemetry data in combination with other data sources in MaxEnt SDMs (e.g. Edren et al., 2010; Jennings \& Veron, 2011) exacerbates over-representation of some regions within a study area, which can cause a severe spatial bias in the collected occurrence data. Spatial bias usually leads to environmental bias because of the over-representation of certain environmental features of the more accessible and extensively surveyed areas. Thus, the difference between available occurrence records and background sampling (i.e. data points taken randomly from the study area) may lead to inaccurate models that in turn may lead to inappropriate management decisions (MacKenzie, 2005; Phillips et al., 2009). Spatial clumping often results in autocorrelation of model residuals (i.e. spatial autocorrelation [SAC]) and affects model quality by inflating model accuracy (Veloz, 2009), leading to type I errors (Dormann et al., 2007) and yielding misleading parameter estimates (Kühn, 2007). This means significance may be assigned to environmental predictors in the SDMs that are simply typical for the region of intensive survey, further resulting in spatial extrapolation errors. These can be omission errors (false negatives; a species is mistakenly 
thought to be absent) or commission errors (false positives: a species is mistakenly thought to be present) (Rondinini et al., 2006). Such errors can have severe consequences for conservation if SDMs are used to delineate areas of high conservation priority (Reddy \& Davalos, 2003; Kremen et al., 2008; Sastre \& Lobo, 2009).

Although sampling bias is a general problem in SDM, particularly in MaxEnt studies, the issue of correcting for this bias has only recently been raised (e.g. Raes \& ter Steege, 2007; Phillips, 2008), and little attention has been given to the evaluation of strategies to correct for uneven sampling effort or compare their efficacy. This is even more remarkable, as recent statistical papers show the equivalence of MaxEnt to point process models and logistic regression (Warton \& Shepherd, 2010; Renner \& Warton, 2013). Thus, accounting for the independence of the records is also a logical step in MaxEnt models. A recent article by Yackulic et al. (2013) revealed that $87 \%$ of MaxEnt models were based on data that were likely to suffer from sample selection bias. Sampling bias can be addressed by reducing the number of occurrence records in oversampled regions using spatial filtering (Dormann et al., 2007; Phillips et al., 2009; Veloz, 2009). This method, however, increases the risk that the number of occurrence records will become too few to build statistically sound models. Alternatively, background data can be manipulated (Phillips et al., 2009; Syfert et al., 2013): Recent releases of MaxEnt allow the inclusion of so-called bias files that allow the user to choose background data with the same bias as occurrence data. This approach has been found to improve model performance for a variety of SDM approaches and species data (Phillips et al., 2009). So far, these two approaches have not yet been compared. In particular, there is a need to understand situations where it is preferable to reduce sampling bias by manipulating occurrence data versus manipulating background data.

To help clarify these situations, we used simulated data where we have full control over the modelled system as well as an example from conservation practice, a recently compiled data from Borneo on Malay civet Viverra tangalunga, a Southeast Asian small carnivore. This species occurs across the island of Borneo, is relatively common compared with other small carnivores and is frequently recorded in primary (Colon, 2002; Brodie \& Giordano, 2011) and disturbed forests (Colon, 2002; Wilting et al., 2010b). Sightings of Malay civets at the edges of oil palm plantations where plantations abut forests have been reported (A. J Hearn, J. Ross \& D. W. Macdonald, unpublished data), but it is generally thought that Malay civets only enter the plantations at night to hunt and need the shelter of the forests during the day. Thus, plantations without nearby forests are considered unsuitable for the species (Augeri, 2005). Survey effort on Borneo is strongly biased towards Sabah, the north-eastern Malaysian state constituting $10 \%$ of Borneo, while large parts of the Indonesian states of central, south, east and west Kalimantan (comprising about two-thirds of Borneo) being little studied. This large dataset thus provided an opportunity to assess the effect of choosing different MaxEnt model thresholds of spatial filtering (option 1) and manipulating background data by introducing bias files for the unsampled background (option 2) on the area predicted as suitable for Malay civets. The simulated data thereby provided an independent means of predictive performance assessment. Model complexity can affect model performance (Reineking \& Schröder, 2006) especially when the number of input layers exceeds the number of occurrence records (Warren \& Seifert, 2011), an effect that is inherently increased by spatial filtering. We thus also assessed the effect of overparameterization on model accuracy in relation to option 1 and option 2. We discuss our results in terms of overpredicting and underpredicting specific areas as a consequence of the different options employed and the implications for conservation planning and management.

\section{METHODS}

\section{Species records}

The study area was Borneo excluding small islands (Fig. 1). We collated 504 occurrence records for Malay civet from over 40 international scientists, museum specimens and several hundred scientific publications in the course of the 1st Borneo Carnivore Symposium 2011, Kota Kinabalu, Malaysia (http://www. fwrc.msstate.edu/borneocarnivoresymposium). To account for varying geographical precision of the records, we divided the data into three categories of precision: (1) $<0.5 \mathrm{~km}$, (2) $0.5-$ $<2.0 \mathrm{~km}$ and (3) $2.0-<5.0 \mathrm{~km}$. We used the 291 occurrence records dating from 2001 to 2011 to match the occurrence record data with land-cover data used in the analysis (Table 1, Fig. 1). This dataset provided the baseline scenario (Table 1); over $60 \%$ of these records were from the Malaysian state of Sabah.

We further simulated data for two species with the same amount of records and geographical clumping in Sabah as the Malay civet, but with different habitat requirements. The first simulated species resembles a range-restricted species of highland Borneo dwelling in undisturbed forests (similar to the Hose's civet Diplogale hosei; hereafter referred to as DHOsim). We randomly placed the records in the large connected upland forest (land-use categories 2, 3 and 4; see below) using ArcGIS 9.3.1. The second simulated species is a lowland species bound to wet forests, such as the flat-headed cat (Prionailurus planiceps; hereafter referred to as PPLsim). We randomly placed the records in lowland forest, peat swamps and mangroves (land-use categories 1, 9 and 10; see below). That means, both simulated species are specific in their habitat needs; however, the range-restricted DHOsim also occupies a narrow niche in many environmental predictors (i.e. lower temperatures and higher precipitation correlating with elevation), especially as we restricted the range to the central highland block on Borneo and excluded highland or montane forests in other parts of Borneo (range restriction; see Fig. S2a in Supporting Information). In 
Figure 1 Malay civet records per landuse category for the three data filtering approaches: no spatial filtering (SF-no, large figure); distance correction by taking only 1 point within a radius of $10 \mathrm{~km}$ shown for Sabah as example (SF-10, small inset left) and additional correction by taking proportionally as many records from Sabah as from the rest of Borneo (SF-bal, small inset middle).

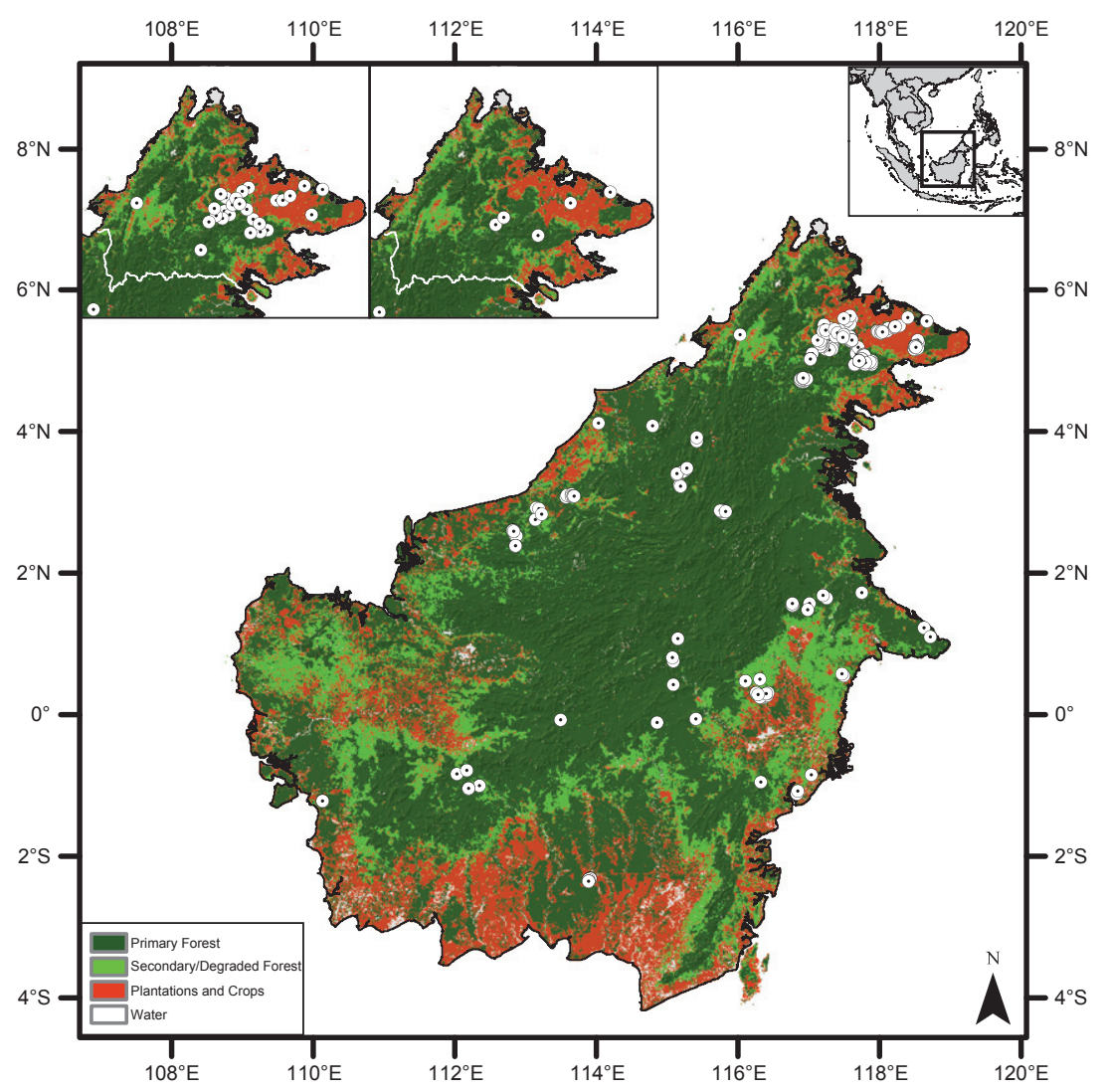

Table 1 Viverra tangalunga records, with the number of records listed by Bornean administrative unit, their spatial precision (categories 1-3) as well as the number of records after reduction in spatial autocorrelation (SAC; SF-no: no spatial filtering applied, SF-10: spatial filtering of records within a radius of $10 \mathrm{~km}, \mathrm{SF}-\mathrm{bal}$ : balanced design reducing the geographical clumping of records in Borneo). For the simulated species DHOsim and PPLsim, we accordingly used 291, 67 and 45 records with the same frequencies distributed in Sabah (i.e. 177, 27 and 5, respectively)

\begin{tabular}{lclc}
\hline & $\begin{array}{l}\text { Baseline } \\
\text { (SF-no) }\end{array}$ & $\begin{array}{l}\text { reduction } \\
\text { (SF-10) }\end{array}$ & $\begin{array}{c}\text { Balanced } \\
\text { (SF-bal) }\end{array}$ \\
\hline Sabah (Malaysia) & 177 & 27 & 5 \\
Sarawak (Malaysia) & 37 & 13 & 13 \\
Kalimantan (Indonesia) & 77 & 27 & 27 \\
Brunei & 0 & 0 & 0 \\
Records in category 1 & 248 & 57 & 37 \\
Records in category 2 & 23 & 4 & 3 \\
Records in category 3 & 20 & 6 & 5 \\
Total & 291 & 67 & 45 \\
\hline
\end{tabular}

contrast, PPLsim does not occupy a specific niche within many of the environmental predictors, because lowland forests, swamps and mangroves occur all over Borneo (see Fig. S2b). Here, the discriminative property of the species' range is the land cover.

\section{Environmental input variables}

We selected environmental variables of potential biological relevance for the distribution of Malay civets, such as climatic, topographical or predictors indicating human impact (Table 2). We used a set of 19 global climate data maps with an interpolated spatial resolution of about $1 \mathrm{~km}^{2}$ (Hijmans et al., 2005). In addition, we created topographical ruggedness and distance to water course maps. Topographical heterogeneity influences the microclimate, local hiding place availability and terrain inaccessibility (human hunters, predators) and might be positively associated with species presence (e.g. Kuemmerle et al., 2010; Pedersen et al., 2007). Distance to water may be essential in providing food resources (e.g. Wilting et al., 2010a). The Topographic Ruggedness Index (TRI, Riley et al., 1999) expresses the elevation difference between adjacent cells (all 8 first-order neighbours within a quadratic grid; Moore neighbourhood) of a 90-m-resolution digital elevation model (DEM; http://srtm.csi.cgiar.org) on a scale ranging from 1 (level) to 7 (extremely rugged). Distance to water courses was calculated from the stream net that was based on a singleflow-direction approach (Hydrologic Analysis in Spatial Analyst ArcView 9.3.1). We set resulting cut-offs to 5,000, 100,000 and 500,000 flow accumulation cells to include small perennial river systems to primary rivers. Resulting water courses had approximate catchment sizes of 42,850 and $4250 \mathrm{~km}^{2}$. We combined the three stream net layers with a layer of major water bodies of Borneo (i.e. lakes and large rivers; country 


\section{S. Kramer-Schadt et al.}

Table 2 Environmental input variables for the complex and reduced modelling scenarios. Environmental predictor variables that were included in both scenarios are marked with a plus $(+)$

\begin{tabular}{|c|c|c|c|}
\hline Variable & $\begin{array}{l}\text { Complex } \\
\text { model ('All') }\end{array}$ & $\begin{array}{l}\text { Reduced model } \\
\text { ('uncorrelated') }\end{array}$ & Reference \\
\hline Bioclim maps & All (1-19) & $1,4,7,13,14,15$ & http://www.worldclim.org/bioclim \\
\hline $\begin{array}{l}\text { Distance to water, based on stream } \\
\text { nets of three different scales: }(1) \\
\text { small water courses with a } \\
\text { catchment size of } 42 \mathrm{~km}^{2},(2) \\
\text { medium rivers (catchment size } \\
850 \mathrm{~km}^{2} \text { ) and (3) main water } \\
\text { courses (catchment size } 4,250 \mathrm{~km}^{2} \text { ) }\end{array}$ & All & $\begin{array}{l}\text { Medium and main } \\
\text { water courses }\end{array}$ & Hijmans et al., (2005) \\
\hline Ruggedness & + & + & Riley et al., (1999) \\
\hline Human population density & + & + & $\begin{array}{l}\text { LandScan } 2007^{\mathrm{TM}} \text { High Resolution } \\
\text { Global Population Data Set, Oak } \\
\text { Ridge National Laboratory, } \\
\text { UT-Battelle, LLC }\end{array}$ \\
\hline Reclassified PALSAR land-cover map & + & + & Hoekman et al., (2009) adapted \\
\hline
\end{tabular}

inland water data of the Digital Chart of the World, www. diva-gis.org) to create three 'distance to water' maps. For land cover, we used the 50-m-resolution PALSAR land-cover map validated for Borneo (Hoekman et al., 2009) from 2007 and updated it with DEM data in 500-m elevation steps to obtain a finer grain of land-cover classification, that is, forest cover was classed into four different categories of lowland, upland, lower montane and upper montane forests, as these classes might be differently influenced by climate, human disturbance and ruggedness. The reclassified land-cover map had the following 17 land-cover classes: (1) lowland forest 0-500 m; (2) upland forest 501-1000 m; (3) lower montane forest 1001-1500 m; (4) upper montane forest $>1500 \mathrm{~m}$; (5) forest mosaics and fragmented or degraded forests $0-500 \mathrm{~m}$; (6) forest mosaics and fragmented or degraded forests 501-1000 m; (7) forest mosaics and fragmented or degraded forests 1001-1500 m; (8) forest mosaics and fragmented or degraded forests > $1500 \mathrm{~m}$; (9) swamp forest; (10) mangrove; (11) old plantations; (12) young plantations and crops; (13) burnt forest area; (14) mixed crops; (15) water and fishponds; (16) water bodies; (17) no data. Human population density data (LandScan $2007^{\mathrm{TM}}$ High Resolution Global Population Data Set, Oak Ridge National Laboratory, UT-Battelle, LLC) were also included, because human presence may negatively impact carnivore presence through forest fragmentation, disturbance and hunting (e.g. Morueta-Holme et al., 2010).

\section{Model scenarios}

We generated systematic scenarios of species distribution predictions by a stepwise combination of all possible options specified below; that is, by spatial filtering and background manipulation (SF and BM), we had three possibilities of filtering or creating background files resulting in nine different scenarios. These scenarios were repeated for the Malay civet and the two simulated species. In addition, the two options (SF and BM) were tested with the full set of environmental input layers as well as a reduced number of uncorrelated input layers for the real dataset of the Malay civet, resulting in 18 scenarios (cf. also results Table 3 ).

\section{Option 1: Spatial filtering (SF)}

We systematically assessed the consequences of spatial clumping by first only using one record within a radius of $10 \mathrm{~km}$ (Table $1,10-\mathrm{km}$ reduction scenario [SF-10]). This radius was chosen because the mean home range size of individual Malay civets is between 1 and $1.5 \mathrm{~km}^{2}$ (Colon, 2002; Jennings et al., 2010), but home ranges were larger in logged forest compared with primary forest (Colon, 2002). To account for differentsized home ranges in different habitats and to ensure spatial independence, we used a conservative approach with $10 \mathrm{~km}$. We retained the location with the greatest precision. Nonetheless, owing to the higher number of field studies from Sabah compared with other Bornean regions, records were still heavily geographically unbalanced, with Sabah containing $>50 \%$ of all records despite covering only about $10 \%$ of the area of Borneo. In a second stage, we thus further reduced the number of records in Sabah by randomly selecting records to produce a sample with the same density as outside of Sabah. As only 40 records were detected outside of Sabah $\left(678,200 \mathrm{~km}^{2}\right)$, we included only five from Sabah $\left(\sim 73,600 \mathrm{~km}^{2}\right.$; Table 1 , balanced scenario [SF-bal]).

Option 2: Background manipulation with bias files (BM)

Generally, the background area for all scenarios was Borneo (Fig. 1). We manipulated the background sampling effort with two alternative species-specific 'bias files' representing the relative sampling effort or record density. Species records were mapped on a $1-\mathrm{km}^{2}$ grid, and each cell was given a value of 1 if it contained a record. We subsequently summed the number 


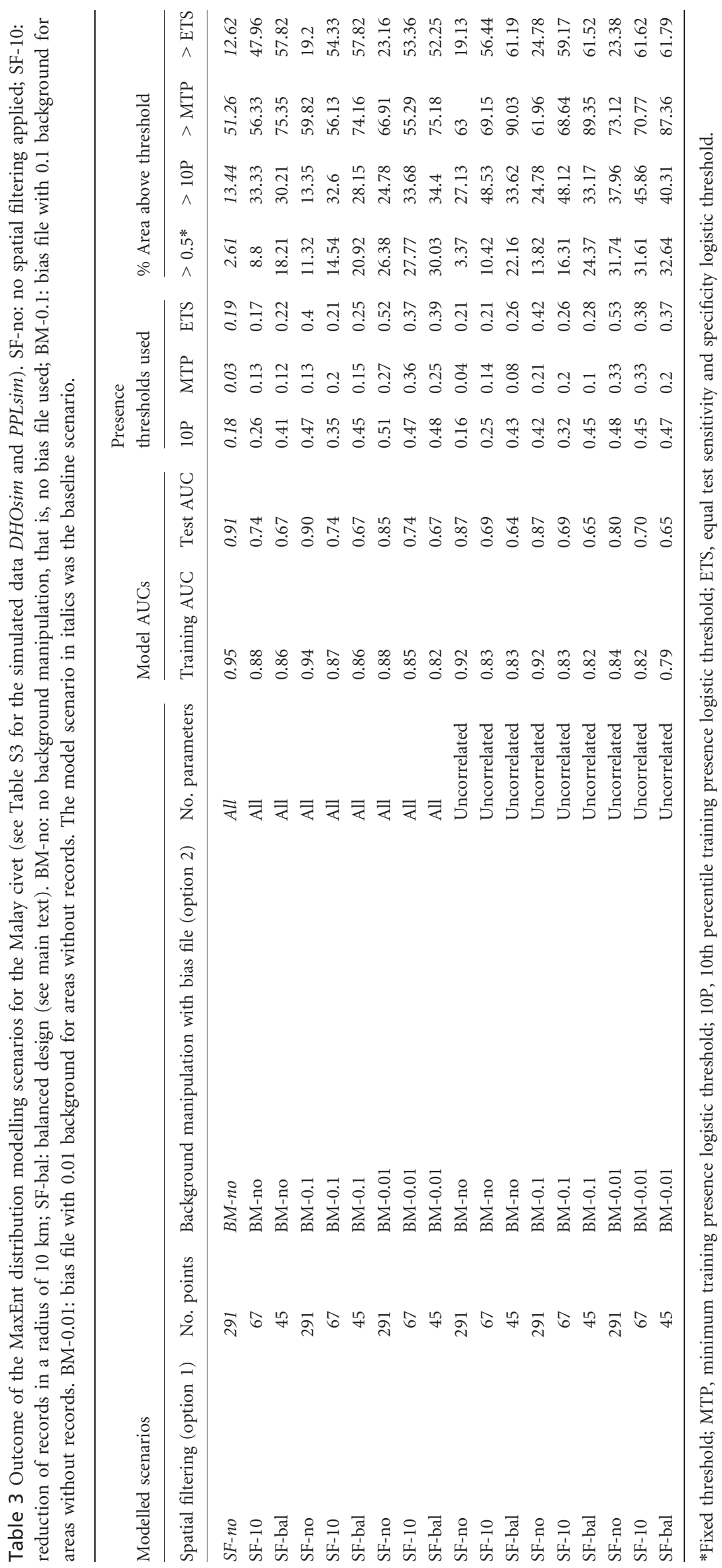


of records across the Moore neighbourhood of each cell to produce a map of 'sampling' density. We used this widthrestricted moving window approach to ensure that only those cells were included in the bias files where we were absolutely sure that the species was sampled. If there was no record, a cell was assigned the value 0.1 , indicating a tenth of the sampling effort of a value of 1 (bias scenario BM-0.1; see Fig. S1). We further assessed the sensitivity of bias files by assigning values of 0.01 to cells with no records (bias scenario BM-0.01) to yield a scenario closer to non-sampling. Scenarios without background manipulation were termed BM-no.

\section{Reducing multicollinearity}

As an alternative to a complex model including all environmental variables ('all' scenario), we produced a reduced version by eliminating correlating variables where Pearson's $|r|>0.75$ (e.g. Dormann et al., 2012; Syfert et al., 2013) (see Table S1). We retained the variable with the most correlations with the other variables. This resulted in the inclusion of only six climatic variables and two water maps (Table 2, 'uncorrelated' scenario).

\section{MaxEnt modelling and model evaluation}

We ran MaxEnt version 3.3.3a (www.cs.princeton.edu/ schapire/ maxent; Phillips et al., 2006) with default settings as follows: random test percentage $=25$; regularization multiplier $=1$; maximum number of background points $=10,000$. We ran 10 replicates and used mean relative occurrence or suitability probabilities predicted for further analyses. As measures of SDM accuracy or discriminative power, respectively, we used the threshold-independent area under the curve (AUC) of the receiver operating characteristic (ROC) plot (Fielding \& Bell, 1997) produced by MaxEnt. Models with an AUC $>0.7$ have good discriminatory power (Hosmer \& Lemeshow, 1989).

To aid model validation and interpretation and to check for robustness of results, we compared four commonly used MaxEnt thresholds to define the percentage of suitable habitat (Liu et al., 2005; Jimenez-Valverde \& Lobo, 2007): (1) MaxEnt relative suitability probability $>0.5$ as a fixed threshold approach corresponding to a temporal and spatial scale of sampling that results in a $50 \%$ chance of the species being present in suitable areas (Elith et al., 2011), that is, unlike true prevalence (Warton \& Shepherd, 2010; Dorazio, 2012), (2) the minimum training presence logistic threshold (MTP), (3) a 10th percentile training presence logistic threshold (10P) and (4) an equal test sensitivity and specificity logistic threshold (ETS).

We then selected three scenarios for model validation (baseline: no background manipulation and no spatial filtering [SF-no BM-no], only background manipulation: bias file with 0.01 background but no spatial filtering [SF-no BM-0.01] or a balanced design: no background manipulation, but with spatial filtering [SF-bal BM-no]). In these three scenarios, we assessed which scenario under-repre- sented non-sampled areas (omission error or false negative, that is, suitable area not correctly predicted) or overpredicted the species range (commission error or false positive, that is, wrongly predicted area that actually is not suitable). For the field records of the Malay civet, we used the following approach to evaluate model accuracy: To assess omission error, we counted how many of the 67 records used in the $10-\mathrm{km}$ reduction approach (Table 1) occurred in non-predicted areas separated by the widely used 10P threshold. We could not assess commission errors without independent test data; therefore, we used the predicted areas (10P threshold) that occurred within oil palm plantations (reportedly unsuitable; Jennings et al., 2010) (land-cover classes 11 and 12, cf. chapter 'Environmental input variables') as an optimistic indicator of commission error. As an independent validation of model accuracy, we used the simulated dataset where the suitable range was predefined. Hence, the omission error is the area defined as suitable but not predicted by the model. In contrast, commission error is the predicted area that is not suitable for the species (see Fig. S2).

\section{RESULTS}

\section{Model scenarios}

\section{Option 1: Spatial filtering}

Use of the full dataset for the Malay civet resulted in a strong geographical clustering of predictions for areas (in our case Sabah) where most records originated, that is, Sabah was assigned the highest suitability (Fig. 2a-c; SF-no scenarios), independent of the threshold used. Spatial filtering of the dataset (SF-10 and SF-bal) resulted in greater representation of non-surveyed areas outside Sabah (Fig. 2a-c). The degree of increase in area predicted as suitable differed depending on thresholds used: balancing the sampling design (SF-bal) doubled the estimated suitable area for the 10P (from $\sim 13 \%$ to $\sim 30 \%$ ) and tripled the area for the ETS (from $\sim 13 \%$ to $\sim 58 \%$ ) threshold. The use of the predictive map with a fixed threshold $>0.5$ increased the estimated suitable area from $\sim 3 \%$ to $18 \%$. Test AUCs were considerably reduced (AUCs < 0.7) when using spatial filtering (Table 3); however, the relative gain contribution (i.e. a goodness-of-fit measure) of the most important variable increased (see Table S2). The same results hold for the two simulated species (Tables S2 and S3, Fig. S3). However, the AUC of the range-restricted species DHOsim did not decrease with spatial filtering, which is due to the narrow response range within the environmental predictors (Table S3).

\section{Option 2: Background manipulation with bias files}

As with spatial filtering, background manipulation increased the predicted distribution area for the Malay civet independent of thresholds, but only if very low values (0.01) were assigned to non-sampled areas (Table 3, Fig. 2a-c). 

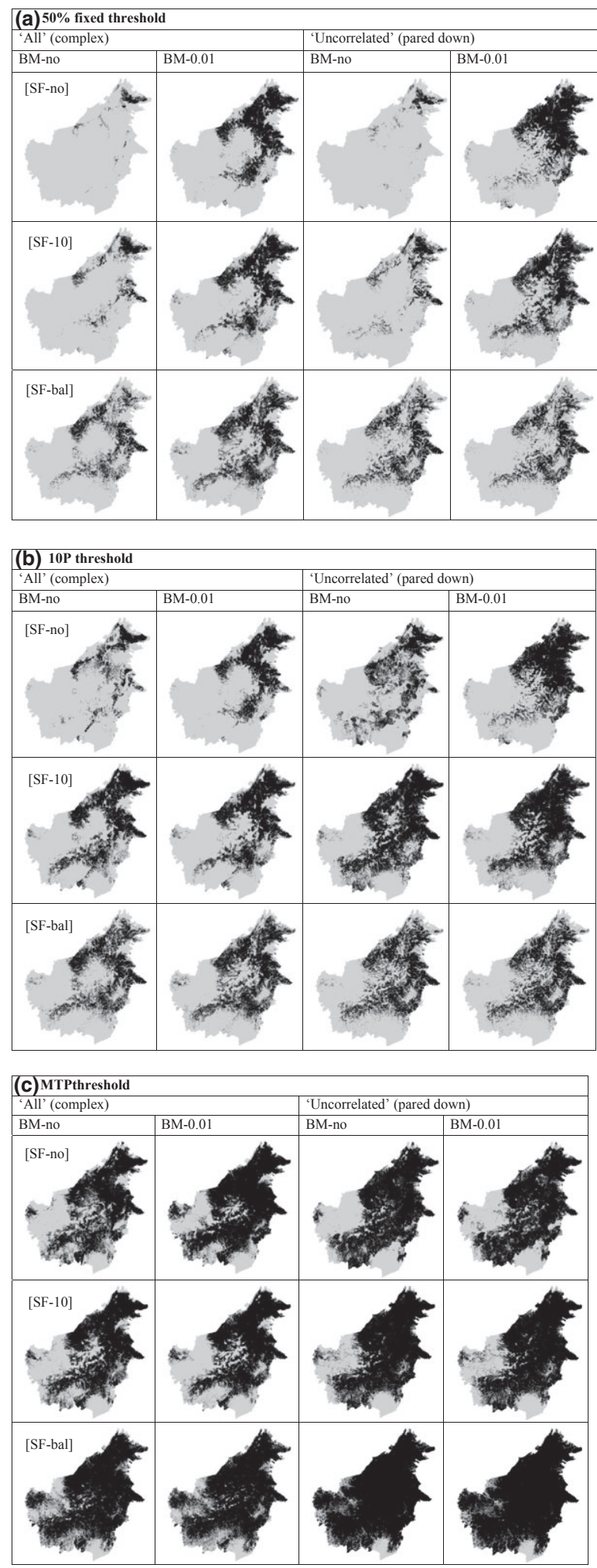

Figure 2 MaxEnt spatial predictions for the Malay civet for different scenarios of data filtering [SF-no, SF-10, SF-bal], background manipulations [BM-no, BM-0.01], thresholds used to separate the map into binary predictions (suitable: black colour, unsuitable: grey colour) $(\mathrm{a}-\mathrm{c})$ and for varying model complexity (left or right columns) (see Fig. S3 for simulated datasets DHOsim and PPLsim).
With background values of 0.1 , the change in area predicted was $<10 \%$ for all thresholds. The impact of bias files was reduced in $10-\mathrm{km}$ reduction scenarios, and background manipulation almost had no further effect on balanced model outcomes (Fig. 2, Table 3). Test AUCs were constant (BM-0.1) or only slightly reduced by $\sim 5 \%$ (BM-0.01, Table 3). Using bias files also put more emphasis on the explanatory power of single variables, that is, the relative gain contribution increased (see Table S2). We observed the same trend for the two simulated species (Tables S2 and S3, Fig. S3).

\section{Reducing multicollinearity}

In contrast to the large effect of spatial filtering of records on modelling results, we observed only minor differences when correlated input variables were eliminated; differences in predicted suitable habitat were slightly greater $(2-5 \%)$ in the reduced than the complex scenarios (Table 3, Fig. 2a-c right side). These minor deviations were consistent across all scenarios. Only in the models without spatial filtering (SF-no) with the 10P threshold did the predicted distribution area increase substantially $(12-14 \%)$ in the parsimonious scenario (Table 3 and Fig. 2b). In contrast, the predicted suitable habitat in the balanced models [SF-bal] with the 10P threshold appeared robust in terms of model complexity (3-6\%). In general, we observed a small decrease in AUC values in parsimonious scenarios compared with complex scenarios $(2-5 \%)$. Due to reduction in environmental input layers, the relative gain of the most important input variables also increased (see Table S2).

In summary, spatial filtering, background manipulation and reducing multicollinearity all increased the area predicted as suitable habitat for the Malay Civet in Borneo as well as for the simulated species. The choice of thresholds to define the percentage of suitable habitat also heavily influenced model results. However, the variation in important environmental predictors was small, with only three predictors consistently being the most important for 18 scenarios. Using a balanced design consistently resulted in the same environmental predictors (Table S2), indicating the robustness of this approach. In the simulations of the range-restricted species DHOsim, the underlying variable 'land cover' was never chosen as the most important one due to the correlation of highland forest with other environmental predictors. In contrast, PPLsim simulations always revealed land cover as the most important one.

\section{Model evaluation}

\section{Malay civet}

Using the 67 occurrence records falling within the predicted distribution area of the $10 \mathrm{P}$ threshold maps of the baseline scenario (SF-no BM-no; Fig. 3a) and background manipulation scenario with 0.01 bias file (SF-10 BM-0.01; Fig. 3b) revealed very low omission errors for Sabah, the area with 


\section{S. Kramer-Schadt et al.}

most records and sampling effort: only one record (SF-no BM-no) or none (SF-no BM-0.01) occurred in an area predicted to be unsuitable (Table 4). In contrast, in the balanced scenario (SF-bal BM-no; Fig. 3c), seven of 27 records within Sabah occurred in non-predicted areas (26\% omission error). The reverse pattern was observed for the 40 records outside Sabah. In the baseline models, 16 (SF-no BM-no) and 14 (SF-no BM-0.01) records were in non-predicted areas ( $40 \%$ and $35 \%$ omission error, respectively), but only two in the balanced scenario (SF-bal BM-no, 5\% omission error; Table 4). Over the whole of Borneo, omission errors were lowest in the balanced scenario. Commission errors were highest for the baseline scenario [SF-no BM-no] for Sabah ( $\sim 20 \%$ oil palm plantations fell within the predicted area) as well as for the rest of Borneo $(\sim 5 \%)$. For Sabah, the background manipulation scenario [SF-no BM-0.01] also resulted in higher commission errors $(\sim 9 \%)$ than the balanced model $(\sim 15 \%)$, whereas for the rest of Borneo, commission errors were more similar (Table 4).

\section{Simulated species}

Regarding the predictive accuracy for the whole of Borneo (column 'Total' in Table S4, Fig. S2), both background manipulation and the balanced design outperformed the baseline scenario without data manipulation. Commission errors were lowest in the balanced design for both simulated datasets. Omission errors were lower for the range-restricted species DHOsim when using bias files, whereas for the PPLsim species with its wide distribution range corresponding with a broad niche in the predictors, the balanced design also outperformed background manipulation with respect to omission errors.

\section{DISCUSSION}

The consequences of sampling bias on SDM performance have increasingly been acknowledged (Kadmon et al., 2003, 2004; Reese et al., 2005; Araujo \& Guisan, 2006), but so far only a few studies have attempted to address sampling bias in MaxEnt models (occurrence record manipulation: Pearson et al., 2007; Edren et al., 2010; background manipulation: Raes \& ter Steege, 2007; Phillips et al., 2009; Clements et al., 2012; Syfert et al., 2013). Here, we simultaneously tested the effects of spatial filtering and manipulating background data under various widely used model selection thresholds. We applied an approach to compare the performance of two strategies coping with uneven sampling effort by combining empirical and simulated data representing two other threatened Bornean carnivores. Sampling bias may not only be a particular problem in studies of rare, elusive or little studied species; observations of common and widespread species may not be considered important and might therefore be under-reported. This reporting bias is quite common for many widespread species and could also have a serious effect on their distribution outputs.

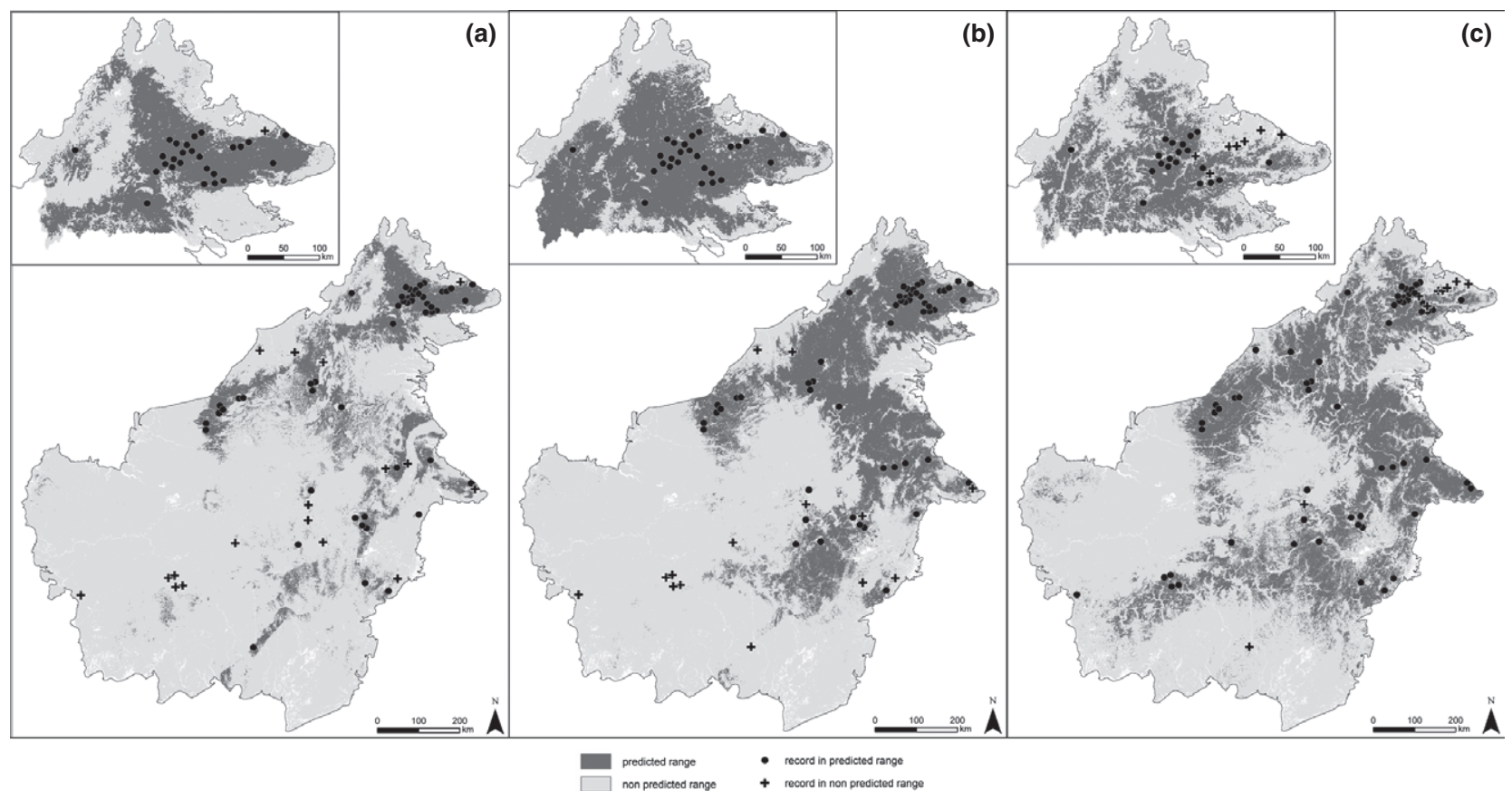

Figure 3 Evaluation dataset of the Malay civet plotted on predictions of three different complex models to assess the impact of a spatial filtering versus background manipulation. The 10P threshold separates suitable (dark grey) and unsuitable (light grey) areas. (a): Baseline scenario without spatial filtering and without bias file [SF-no BM-no], (b): no spatial filtering but including a bias file [SF10 BM-0.01], C: balanced design [SF-bal BM-no]. Dot: Species record correctly predicted in suitable area (true presence), Cross: species record in area predicted to be unsuitable (omission error) (see Fig. S2 for the simulated species DHOsim and PPLsim). 
Table 4 Evaluation of spatial extrapolation errors (omission and commission errors) in three different scenarios (baseline, background manipulation and balanced) separated for Sabah and the rest of Borneo for the Malay civet (see Table S4 for the simulated data DHOsim and PPLsim). We used the 10th percentile training presence logistic threshold (10P) to create binary maps separating raster cells into predicted as suitable or unsuitable. To assess omission errors, we calculated how many presence points [using 67 independent records from spatial filtering (10 km reduction)] occurred in predicted or non-predicted areas. As an indicator of commission errors, we used the predicted areas that lay within oil palm plantations (supposedly unsuitable for Malay civets)

\begin{tabular}{|c|c|c|c|}
\hline & Scenario & & \\
\hline & $\begin{array}{l}\text { Baseline: } \\
\text { No spatial filtering, no bias file } \\
\text { [SF-no BM-no]; Fig. 3a } \\
\text { Sabah }\end{array}$ & $\begin{array}{l}\text { Background manipulation: } \\
\text { No spatial filtering, bias file with } 0.01 \\
\text { [SF-no BM-0.01]; Fig. 3b }\end{array}$ & $\begin{array}{l}\text { Balanced: } \\
\text { Spatial filtering, no bias file } \\
\text { [SF-bal BM-no]; Fig. 3c }\end{array}$ \\
\hline No. of records in suitable areas & 26 & 27 & 20 \\
\hline No. of records in non-predicted areas & 1 & 0 & 7 \\
\hline $\begin{array}{l}\text { Omission error (\% records in } \\
\text { unsuitable areas per total } \\
\text { number of records) }\end{array}$ & $4 \%$ & $0 \%$ & $26 \%$ \\
\hline Predicted suitable area $\left[\mathrm{km}^{2}\right]$ & 39,062 & 54,133 & 36,828 \\
\hline Predicted oil palm plantation $\left[\mathrm{km}^{2}\right]$ & 7848 & 10,292 & 5398 \\
\hline \multirow{2}{*}{$\begin{array}{l}\text { Commission error ( } \% \text { oil palm } \\
\text { plantation that fell into the } \\
\text { predicted area) }\end{array}$} & $20.1 \%$ & $19.0 \%$ & $14.7 \%$ \\
\hline & Rest of Borneo & & \\
\hline No. of records in suitable areas & 24 & 26 & 38 \\
\hline No of records in non-predicted areas & 16 & 14 & 2 \\
\hline $\begin{array}{l}\text { Omission error ( } \% \text { records in } \\
\text { unsuitable areas per total } \\
\text { number of records) }\end{array}$ & $40 \%$ & $35 \%$ & $5 \%$ \\
\hline Predicted suitable area $\left[\mathrm{km}^{2}\right]$ & 73,640 & 224,896 & 160,369 \\
\hline Predicted oil palm plantation $\left[\mathrm{km}^{2}\right]$ & 3860 & 10,363 & 5989 \\
\hline \multirow{2}{*}{$\begin{array}{l}\text { Commission error ( } \% \text { oil palm } \\
\text { plantation that fell into } \\
\text { the predicted area) }\end{array}$} & $5.2 \%$ & $4.6 \%$ & $3.7 \%$ \\
\hline & Total (whole Borneo) & & \\
\hline No. of records in suitable areas & 50 & 53 & 58 \\
\hline No of records in non-predicted areas & 17 & 14 & 9 \\
\hline $\begin{array}{l}\text { Omission error (\% records in unsuitable } \\
\text { areas per total number of records) }\end{array}$ & $25 \%$ & $21 \%$ & $13 \%$ \\
\hline Predicted suitable area $\left[\mathrm{km}^{2}\right]$ & 112,702 & 214,502 & 261,724 \\
\hline Predicted oil palm plantation $\left[\mathrm{km}^{2}\right]$ & 11,708 & 16,281 & 15,761 \\
\hline $\begin{array}{l}\text { Commission error }(\% \text { oil palm } \\
\text { plantation that fell into } \\
\text { the predicted area) }\end{array}$ & $10.4 \%$ & $7.6 \%$ & $6.0 \%$ \\
\hline
\end{tabular}

The results of our species distribution models showed that overall predictive performance was highest in modelling scenarios where spatial filtering accounted for sampling biases (option 1), followed by those where sampling bias was reduced by background manipulation (option 2) and lowest in the baseline scenarios that did not correct for sampling bias.

However, the performance depended also on the species considered. Proportional record filtering had superior predictive performance for species that used a wide range within the environmental predictors, such as the Malay civet or the simulated lowland species PPLsim. Here, balancing the geo- graphical origin prevents overemphasizing environmental predictors that putatively correlate with the species' distribution simply due to sampling bias. Thus, filtering outweighed the negative effects of sampling bias and substantially reduced omission errors (suitable areas not predicted by models), particularly in areas where surveying was limited. Higher omission errors can have serious negative consequences for conservation because remote areas with scant surveying effort, which may be potentially important for a species, may be neglected.

On the other hand, especially for range-restricted species (here, DHOsim), spatial clumping of records may be an 
ecological signal (Dormann et al., 2007), and filtering the records can weaken the prediction; in these cases, it would be preferable to use a bias file. However, this implies prior knowledge about the species' distribution, which often is not available. In the case of the Malay civet, use of a bias file resulted in higher commission errors (areas mistakenly predicted to be suitable): Only a few records existed from oil palm plantations (all in close vicinity to forests; cf. Jennings et al., 2010), and thus, plantations were downweighted by the bias files to rarely sampled areas, equally in and outside Sabah. However, the concentration of records in Sabah led to greater weight on distinct climatic variables such that oil palm plantations in Sabah were predicted to be more suitable than those outside Sabah. Commission errors may have particular negative consequences because they can create the false assumption that a species occurs in protected areas or intact habitat, potentially leading to parts of its range being ignored by conservation efforts.

Our results clearly highlight that spatial filtering of clumped records (balanced scenario) minimized both omission and commission errors for Borneo-wide predictions and was robust in regard to consistently identifying the most important predictor. Thus, accounting for sampling bias is needed, and a conservative approach (balanced design) is recommended, despite the putatively lower predictive performance according to the test AUC values. It is worth mentioning that as a consequence of reducing the number of input records to achieve a balanced design, the predictive power of the model is reduced (Hernandez et al., 2006). In this respect, the most commonly used metric for model quality (test AUC) can be misleading (Lobo et al., 2007) and can poorly represent the underlying biology of the system being studied (Warren \& Seifert, 2011).

Another argument for recommending a balanced design, rather than only background manipulation, is the arbitrary values that have to be set for bias files and the arbitrary way in which they are created when only presence records are available. It is exactly the putative advantage of MaxEnt in comparison with presence-absence or occupancy models that redounds to its disadvantage when used without caution. The values in the bias file (cf. see Option 2: Background manipulation with bias files (BM) in the methods section) have to match sampling effort, which is difficult to estimate when dealing with records stemming from different spatiotemporal scales or occasional sightings. Often, the distribution of records is set as a proxy for sampling effort. For example, for the Malayan tapir Tapirus indicus, Clements et al. (2012) used a weighted Gaussian distance kernel based on presence records and tapir's home range size and scaled their bias file between 1 (non- or undersampled areas) and 100 (clumped presence records). We used a next-neighbour approach assuming higher sampling effort around records, resulting in at least ten (background value 0.1) or 100 (background value 0.01) times less sampling effort in non- or undersampled areas. The comparison between our two background value scenarios (Table 3) showed that the arbitrary estimate for sampling effort influenced model results. There is scope to improve the precision with which bias files reflect sampling effort, for example, by accounting for trap nights if the records come predominantly from camera-trapping studies. However, when a dataset is composed of opportunistic sightings and road kills alongside structured sampling (e.g. typically from scientific studies), as investigations of little known species typically are, it is effectively impossible to obtain objective values for sampling effort in different areas. We recommend further investigations of the effect of differently created bias files.

Increased model complexity may lead to overfitting, which involves using too many environmental input variables with too few occurrence records. For example, Warren \& Seifert (2011) found that overparameterization is generally less problematic than underparameterization. The exception occurred when model complexity (in terms of the number of environmental input variables) approached or exceeded the number of records available for model construction, in which case less complex models performed better (see also Reineking \& Schröder, 2006). In this study, we evaluated the impact of model complexity and showed that the area predicted as suitable was less affected if occurrence records were spatially independent and stratified throughout the area of inference (balanced model). In contrast, the baseline model predictions were more sensitive to model complexity, and bias in occurrence predictions increased with model complexity.

The selection of a threshold for assessing areas of potentially suitable habitat is another crucial aspect of the assessment of the output of SDMs (Liu et al., 2005) and is needed for any model application, for example, in conservation. We used several thresholds to assess whether spatial autocorrelation of occurrence records, based on uneven sampling, was a problem independent of the specific threshold selected. Although great differences were observed in the percentage of area predicted to be suitable, the overall effect was consistent for all thresholds; that is, areas with a proportionally greater number of records were overpredicted, and non-surveyed areas were underpredicted, particularly if no correction of sampling bias was applied (baseline models).

\section{CONCLUSIONS}

We recommend that in situations with a strong sampling bias towards some regions or environmental features (e.g. survey and therefore records mainly distributed in a certain land-cover type), spatial clumping of records should be reduced in datasets that are used for MaxEnt model calibration. If many occurrence records are available, our results demonstrate that spatial filtering and balancing of occurrence data are preferred relative to background manipulation. If only few spatially clustered occurrence records are available and spatial filtering is impossible, the manipulation of the background dataset seems to be the second best option. Background manipulation decreased the risk of omission errors for the range-restricted species occupying a narrow 
niche within many environmental predictors, but increased it for the species with a generalist response in many predictors; therefore, any conclusions regarding areas suitable for conservation ought to be made with caution. Our study acknowledges the potential of MaxEnt as a powerful tool in SDM and highlights the importance of accounting for sampling bias to help reduce omission and commission errors and thus enhances the accuracy of species conservation and management.

\section{ACKNOWLEDGEMENTS}

We thank Gabriella Fredriksson, Jedediah Brodie, William J. McShea, Tim van Berkel and the Heart of Borneo Project, Rob Stuebing and Deni Wahyudi of the REA KalTim Conservation Department for providing Malay Civet records used for this study. Ana Rodrigues gave useful advice on omission and commission errors. We thank Manuela Fischer for support in the final GIS analyses. Further, we thank all participants of the 1st Borneo Carnivore Symposium (BCS) 2011, Kota Kinabalu, Sabah, Malaysia, for the insightful discussions on and after the symposium. We are indebted to the Sabah Wildlife Department to co-organize the BCS together with the Cat-, Small Carnivore- and Otter-IUCN/SSC Specialist Groups and the Leibniz Institute for Zoo and Wildlife Research. Financial support for the BCS was provided by the following institutions: Benta Wawasan Sdn Bhd; British Ecological Society; Chester Zoo The North England Zoological Society; Cleveland Metroparks; The Clouded Leopard Project; Columbus Zoo; Department of Wildlife, Fisheries and Aquaculture, Flora Blossom Sdn Bhd; Forest and Wildlife Research Center, Mississippi State University; Houston Zoo; KTS Plantation Sdn Bhd; Leibniz Institute for Zoo and Wildlife Research; Malaysia Airlines; Nashville Zoo; Point Defiance Zoo and Aquarium; Shared Earth Foundation; The Usitawi Network; Wild Cat Club; WWF-Germany; WWF-Malaysia. DWM, $\mathrm{AJH}$ and JR warmly acknowledge the support of the Recanati-Kaplan Foundation and the Woodspring Trust.

\section{REFERENCES}

Araujo, M.B. \& Guisan, A. (2006) Five (or so) challenges for species distribution modelling. Journal of Biogeography, 33, 1677-1688.

Augeri, D.M.. 2005. On the biogeographic ecology of the Malayan sun bear. Ph.D. Dissertation. School of Biological Sciences, University of Cambridge, Cambridge, UK. 330 pp.

Baasch, D.M., Tyre, A.J., Millspaugh, J.J., Hygnstrom, S.E. \& Vercauterenm, K.C. (2010) An evaluation of three statistical methods used to model resource selection. Ecological Modelling, 221, 565-574.

Bateman, B.L., VanDerWal, J. \& Johnson, C.N. (2011) Nice weather for bettongs: using weather events, not climate means, in species distribution models. Ecography, 35, 306314.
Brodie, J. \& Giordano, A. (2011) Small carnivores of the Maliau Basin, Sabah, Borneo, including a new locality for Hose's Civet Diplogale hosei. Small Carnivore Conservation, 44, 1-6.

Clements, G.R., Rayan, D.M., Aziz, S.A., Kawanishi, K., Traeholt, C., Magintatn, D., Yazi, M.F.A. \& Tingley, R. (2012) Predicting the distribution of the Asian Tapir (Tapirus indicus) in Peninsular Malaysia using maximum entropy modelling. Integrative Zoology, 7, 400-406.

Colon, C.P. (2002) Ranging behaviour and activity of the Malay civet (Viverra tangalunga) in a logged and an unlogged forest in Danum Valley, East Malaysia. Journal of Zoology, 257, 473-485.

Dorazio, R.M. (2012) Predicting the geographic distribution of a species from presence-only data subject to detection errors. Biometrics, 68, 1303-1312.

Dormann, C.F., McPherson, J.M., Araujo, M.B., Bivand, R., Bolliger, J., Carl, G., Davies, R.G., Hirzel, A., Jetz, W., Kissling, W.D., Kuehn, I., Ohlemueller, R., Peres-Neto, P.R., Reineking, B., Schroeder, B., Schurr, F.M. \& Wilson, R. (2007) Methods to account for spatial autocorrelation in the analysis of species distributional data: a review. Ecography, 30, 609-628.

Dormann, C.F., Elith, J., Bacher, S., Buchmann, C., Carl, G., Carre, G., Garcia Marquez, J.R., Gruber, B., Lafoourcade, B., Leitao, P.J., Münkemüller, T., Mcclean, C., Osborne, P.E., Reineking, B., Schröder, B., Skidmore, A.K., Zurell, D. \& Lautenbach, S. (2012) Collinearity: a review of methods to deal with it and a simulation study evaluating their performance. Ecography, 35, 1-20.

Edren, S.M.C., Wisz, M.S., Teilmann, J., Dietz, R. \& Söderkvist, T. (2010) Modelling spatial patterns in harbour porpoise satellite telemetry data using maximum entropy. Ecography, 33, 698-708.

Elith, J. \& Leathwick, J.R. (2009) Species distribution models: ecological explanation and prediction across space and time. Annual Review of Ecology and Systematics, 40, 677-697.

Elith, J., Graham, C.H., Anderson, R.P. et al. (2006) Novel methods improve prediction of species' distributions from occurrence data. Ecography, 29, 129-151.

Elith, J., Phillips, S., Hastie, T., Dudik, M., Chee, Y.E. \& Yates, C.J. (2011) A statistical explanation of MaxEnt for ecologists. Diversity and Distributions, 17, 43-57.

Fielding, A.H. \& Bell, J.F. (1997) A review of methods for the assessment of prediction errors in conservation presence/ absence models. Environmental Conservation, 24, 38-49.

Franklin, J. (2009) Mapping species distributions. spatial inference and prediction. Cambridge University Press, New York.

Graham, C.H., Elith, H.J., Hijmans, R.J., Guisan, A., Peterson, A.T., Loiselle, B.A. \& The NCEAS Predicting Species Distributions Working Group (2008) The influence of spatial errors in species occurrence data used in distribution models. Journal of Applied Ecology, 45, 239-247.

Güthlin, D., Knauer, F., Kneib, T., Küchenhoff, H., Kaczensky, P., Rauer, G., Jonozovic, M., Mustoni, A. \& Jerina, K. 
(2011) Estimating habitat suitability and potential population size for brown bears in the Eastern Alps. Biological Conservation, 144, 1733-1741.

Hernandez, P.A., Graham, C.H., Master, L.L. \& Albert, D.L. (2006) The effect of sample size and species characteristics on performance of different species distribution modeling methods. Ecography, 29, 773-785.

Hijmans, R.J., Cameron, S.E., Parra, J.L., Jones, P.G. \& Jarvis, A. (2005) Very high resolution interpolated climate surfaces for global land areas. International Journal of Climatology, 25, 1965-1978.

Hoekman, D., Vissers, M. \& Wielaard, N. (2009) PALSAR land cover mapping methodology validation study Borneo. Wageningen University, The Netherlands. pp. 1-112.

Hosmer, D.W. \& Lemeshow, S. (1989) Applied logistic regression. Wiley, New York.

$\mathrm{Hu}$, J. \& Jiang, Z. (2011) Climate change hastens the conservation urgency of an endangered ungulate. PLoS ONE, 6, e22873.

Jennings, A.P. \& Veron, G. (2011) Predicted distributions and ecological niches of 8 civet and mongoose species in Southeast Asia. Journal of Mammalogy, 92, 316-327.

Jennings, A.P., Zubaid, A. \& Veron, G. (2010) Ranging behaviour, activity, habitat use, and morphology of the Malay civet (Viverra tangalunga) on Peninsular Malaysia and comparison with studies on Borneo and Sulawesi. Mammalian Biology, 75, 437-446.

Jimenez-Valverde, A. \& Lobo, J.M. (2007) Threshold criteria for conversion of probability of species presence to eitheror presence-absence. Acta Oecologica, 31, 361-369.

Kadmon, R., Farber, O. \& Danin, A. (2003) A systematic analysis of factors affecting the performance of climatic envelope models. Ecological Applications, 13, 853-867.

Kadmon, R., Farber, O. \& Danin, A. (2004) Effect of roadside bias on the accuracy of predictive maps produced by bioclimatic models. Ecological Applications, 14, 401-413.

Kalkvik, H.M., Stout, I.J., Doonan, T.J. \& Parkinson, C.L. (2011) Investigating niche and lineage diversification in widely distributed taxa: phylogeography and ecological niche modeling of the Peromyscus maniculatus species group. Ecography, 34, 1-11.

Kremen, C., Cameron, A., Moilanen, A. et al. (2008) Aligning conservation priorities across taxa in Madagascar with high-resolution planning tools. Science, 320, 222-226.

Kühn, I. (2007) Incorporating spatial autocorrelation may invert observed patterns. Diversity and Distributions, 13, 66-69.

Kuemmerle, T., Perzanowski, K., Chaskovskyy, O., Ostapowicz, K., Halada, L., Bashta, A.-T., Kruhlov, I., Hostert, P., Waller, D.M. \& Radeloff, V.C. (2010) European Bison habitat in the Carpathian Mountains. Biological Conservation, 143, 908916.

Li, W. \& Guo, Q.E.C. (2011) Can we model the probability of presence of species without absence data? Ecography, 34, 1096-1105.
Liu, C., Berry, P.M., Dawson, T.P. \& Pearson, R.G. (2005) Selecting thresholds of occurrence in the prediction of species distributions. Ecography, 28, 385-393.

Lobo, J.M., Jimenez-Valverde, A. \& Real, R. (2007) AUC: a misleading measure of the performance of predictive distribution models. Global Ecology \& Biogeography, 17, 145151.

MacKenzie, D.I. (2005) What are the issues with presenceabsence data for wildlife managers? Journal of Wildlife Management, 63, 849-860.

Morueta-Holme, N., Flojgaard, C. \& Svenning, J.C. (2010) Climate change risks and conservation implications for a threatened small-range mammal species. PLoS ONE, 5, e10360.

Pearson, R.G., Raxworthy, C.J., Nakamura, M. \& Peterson, A.T. (2007) Predicting species distributions from small numbers of occurrence records: a test case using cryptic geckos in Madagascar. Journal of Biogeography, 34, 102-117.

Pedersen, A.O., Jepsen, J.U., Yoccoz, N.G. \& Fuglei, E. (2007) Climate Change Risks and Conservation Implications for a Threatened Small-Range Mammal Species. Canadian Journal of Zoology, 85, 122-132.

Phillips, S.J. (2008) Transferability, sample selection bias and background data in presence-only modelling: a response to Peterson et al. (2007). Ecography, 31, 272-278.

Phillips, S.J., Anderson, R.P. \& Schapire, R.E. (2006) Maximum entropy modeling of species geographic distributions. Ecological Modelling, 190, 231-259.

Phillips, S.J., Dudik, M., Elith, J., Graham, C.H., Lehmann, A., Leathwick, J. \& Ferrier, S. (2009) Sample selection bias and presence-only distribution models: implications for background and pseudo-absence data. Ecological Applications, 19, 181-197.

Raes, N. \& ter Steege, H. (2007) A null-model for significance testing of presence-only species distribution models. Ecography, 30, 727-736.

Reddy, S. \& Davalos, L.M. (2003) Geographical sampling bias and its implications for conservation priorities in Africa. Journal of Biogeography, 30, 1719-1727.

Reese, G.C., Wilson, K.R., Hoeting, J.A. \& Flather, C.H. (2005) Factors affecting species distribution predictions: a simulation modeling experiment. Ecological Applications, 15, 554-564.

Reineking, B. \& Schröder, B. (2006) Constrain to perform: regularization of habitat models. Ecological Modelling, 193, 675-690.

Renner, I.W. \& Warton, D.I. (2013) Equivalence of MAXENT and poisson point process models for species distribution modeling in ecology. Biometrics, 69, 274-281.

Riley, S.J., De Gloria, S.D. \& Elliot, R. (1999) A terrain ruggedness that quantifies topographic heterogeneity. Intermountain Journal of Science, 5, 23-27.

Rondinini, C., Wilson, K.A., Boitani, L., Grantham, H. \& Possingham, H.P. (2006) Tradeoffs of different types of 
species occurrence data for use in systematic conservation planning. Ecology Letters, 9, 1145.

Royle, J.A., Chandler, R.B., Yackulic, C. \& Nichols, J.D. (2012) Likelihood analysis of species occurrence probability from presence-only data for modelling species distributions. Methods in Ecology and Evolution, 3, 545-554.

Ruiz-Gutierrez, V. \& Zipkin, E.F. (2011) Detection biases yield misleading patterns of species persistence and colonization in fragmented landscapes. Ecosphere, 2, 1-14.

Sastre, P. \& Lobo, J.M. (2009) Taxonomist survey biases and the unveiling of biodiversity patterns. Biological Conservation, 142, 462-467.

Syfert, M.M., Smith, M.J. \& Coomes, D.A. (2013) The effects of sampling bias and model complexity on the predictive performance of MaxEnt species distribution models. PLoS ONE, 8, e55158.

Veloz, S.D. (2009) Spatially autocorrelated sampling falsely inflates measures of accuracy for presence-only niche models. Journal of Biogeography, 36, 2290-2299.

Warren, D.L. \& Seifert, S.N. (2011) Ecological niche modeling in Maxent: the importance of model complexity and the performance of model selection criteria. Ecological Applications, 21, 335-342.

Warton, D.I. \& Shepherd, L.C. (2010) Poisson point process models solve the "pseudo-absence problem" for presenceonly data in ecology. The Annals of Applied Statistics, 4, 1383-1402.

Wilting, A., Cord, A., Hearn, A.J., Hesse, D., Mohamed, A., Traeholdt, C., Cheyne, S.M., Sunarto, S., Jayasilan, M.-A., Ross, J., Shapiro, A.C., Sebastian, A., Dech, S., Breitenmoser, C., Sanderson, J., Duckworth, J.W. \& Hofer, H. (2010a) Modelling the species distribution of flat-headed cats (Prionailurus planiceps), an endangered South-East Asian small felid. PLoS ONE, 5, e9612.

Wilting, A., Samejima, H. \& Mohamed, A. (2010b) Diversity of Bornean viverrids and other small carnivores in Deramakot Forests Reserve, Sabah, Malaysia. Small Carnivore Conservation, 42, 10-13.

Wisz, M.S., Hijmans, R.J., Li, J., Peterson, A.T., Graham, C.H., Guisan, A. \& The NCEAS Predicting Species Distributions Working Group (2008) Effects of sample size on the performance of species distribution models. Diversity and Distribution, 14, 763-773.

Yackulic, C.B., Chandler, R., Zipkin, E.F., Royle, J.A., Nichols, J.D., Campbell Grant, E.H. \& Veran, S. (2013) Presence-only modelling using MAXENT: when can we trust the inferences? Methods in Ecology and Evolution, 4, 236-243.

\section{SUPPORTING INFORMATION}

Additional Supporting Information may be found in the online version of this article:

Table S1 Pearson's product-moment correlation $r$ matrix of environmental input layers.

Table S2. Three most important variables and their relative contributions (\%) of the environmental variables to the MaxEnt models.

Table S3. Outcome of the MaxEnt distribution models for the simulated data DHOsim and PPLsim.

Table S4. Evaluation of spatial extrapolation errors (omission and commission errors) in three different scenarios (baseline, background manipulation and balanced) for the simulated data (DHOsim and PPLsim) separated for Sabah and the rest of Borneo.

Figure S1. Example of bias file.

Figure S2. Predefined suitable areas of (a) a range-restricted species occurring in mountainous forests (DHOsim) and (b) a lowland species dwelling in peat swamps, mangroves and lowland forests (PPLsim).

Figure S3. MaxEnt spatial predictions of the simulated datasets DHOsim and PPLsim for the different scenarios.

\section{BIOSKETCH}

All authors of this manuscript are interested in the distribution and conservation of Bornean carnivores and in the application of species distribution modelling as a tool to improve the efficiency of conservation planning.

Authors' contributions: S.K-S and A.W. conceived the ideas, led the analysis and wrote the paper. J.N., J.L., V.R., M.L., I.H., B.S. and A.K.S. helped to perform the modelling and GIS analyses. J.D.P., D.M.A., S.M.C., A.J.H., J.R, D.W.M., J.M., J.E., A.J.M., G.S., R.R., H.B., R.A., H.S., J.W.D., C.B-W., J.L.B. and H.H contributed to data collection and revised the final manuscript.

Editor: Mark Robertson 